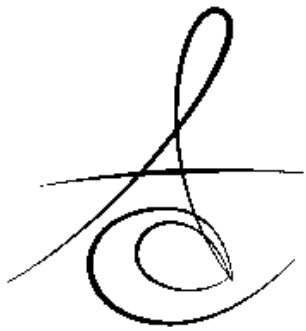

\title{
BİR SELF-ETCH ADEZIVİN FARKLI SAKLANMA KOŞULLARININ DENTİNE BAĞLANMA DAYANIMI ÜZERİNE ETKİSİ
}

\section{THE EFFECT OF DIFFERENT STORAGE CONDITIONS ON THE DENTIN BOND STRENGTH OF A SELF-ETCH ADHESIVE}

\author{
Dr. ÖZcan KARATAŞ ${ }^{*}$ \\ Yrd. Doç. Dr. Merve İşCAN YAPAR*
}

Prof. Dr. Yusuf Ziya BAYINDIR*

Makale Kodu/Article code: 3101

Makale Gönderilme tarihi: 03.11.2016

Kabul Tarihi: 08.02.2017

\section{öz}

Amaç: Çalışmanın amacı farklı koşullarda bekletilen bir Self-Etch adezivin dentin makaslama bağlanma dayanımına etkisini değerlendirmektir.

Gereç ve Yöntem: Çalışmada çekilmiş 40 adet sağlam insan molar dişi kullanıldı. Dişlerin dentin yüzeyi açığa çıkarıldı ve oklüzal yüzeyleri üstte kalacak şekilde akrilik rezin bloklara gömüldü. Ardından örnekler rastgele 5 gruba bölündü. Self-Etch adeziv (Clearfil $\mathrm{S}^{3}$ Bond, Kuraray Dental, Okayama, Japonya) ve bir nanohibrit kompozit (Grandio; Voco, Cuxhaven, Almanya) $3 \mathrm{~mm}$ çapında, $4 \mathrm{~mm}$ yüksekliğinde bir kalıp yardımıyla dentin yüzeyine uygulandı. Gruplardan birine adeziv sürülmesinin ardından kompozit rezin uygulanarak LED ışık cihazıyla (3M Espe, Seefeld, Almanya) polimerizasyon tamamland. 24 saat distile suda bekletilen örneklerin universal test cihazı (Instron Corp. Canton, MA) ile makaslama bağlanma dayanımı ölçüldü. Ardından adezivlerden biri buzdolabında, diğeri ise oda sıcaklığında bekletildi. 1 ay ve 6 ay sonunda her adeziv birer gruba uygulanarak makaslama bağlanma dayanımı yeniden ölçüldü. Veriler kaydedilerek SPSS 20 yazılımıyla tek yönlü Varyans analizi yapıldı ( $a=0.05$ ).

Bulgular: En yüksek bağlanma dayanımı 24 saat sonra hazırlanan örneklerde görüldü (18,35 MPa). 1 ay sonrasında, test sonuçlarına göre buzdolabı sıcaklığında bekletilen adeziv ile hazırlanan örneklerle oda sıcaklığında bekletilen adeziv ile hazırlanan örnekler arasında istatistiksel fark bulunmazken ( $p>0.05)$, oda sıcaklığında 6 ay bekletilme sonucunda bağlanma dayanımının anlamlı derecede daha düşük olduğu gözlendi $(p<0.05)$.

Sonuç: Saklama koşulları kompozit restorasyonun dentine bağlanma dayanımını etkilemektedir. Adezivler üretici talimatlarına uygun bir şekilde buzdolabında saklanmalıdır.

Anahtar kelimeler: Self-Etch adeziv; makaslama bağlanma dayanımı; nanohibrit kompozit

\section{ABSTRACT}

Aim: This study evaluated the effect of different storage conditions on dentin shear bond strength of a Self-Etch adhesive.

Material and Methods: Forty extracted non-caries human molars were used in this study. Flat dentin surfaces were prepared on all teeth and embedded in acrylic resin blocks with the occlusal surfaces facing up. The samples were divided randomly into 5 groups $(n=8)$. A Self-etch adhesive (Clearfil $S^{3}$ Bond, Kuraray Dental, Okayama, Japan) and a nanohybrid composite resin (Grandio; Voco, Cuxhaven, Almanya) was applied on dentin surface with $3 \mathrm{~mm}$ diameter and $4 \mathrm{~mm}$ height in a mold. In the first group, composite resin was applied after adhesive and polymerized with LED curing unit (3M Espe, Seefeld, Germany). Samples were stored in distilled water for 24 hours and then shear bond test was applied with a universal testing machine. After this, one of the adhesive was refrigerated and the other one was stored at room temperature. After 1 month and 6 months each adhesive was applied on one group and shear test was performed. Data were recorded and one-way ANOVA test was done with SPSS 20 software $(a=0.05)$.

Results: The highest bond strength was observed in samples prepared after 24 hours (18,35 MPa). After 1 month, according to the results, there was no significant difference between samples prepared with the adhesive stored at refrigerated temperature or room temperature $(p>0.05)$, while bond strength values of room temperature after 6 months' group were significantly lower than the others groups $(p<0.05)$.

Conclusion: Storage conditions of bonding adhesives are important factors for the bond strength of composite resins to dentin. The adhesives should be stored in the refrigerator as recommended by the manufacturer's instructions.

Keywords: Self-Etch adhesive; shear bond strength; nanohybrid composite

\footnotetext{
* Atatürk Üniversitesi Diş hekimliği Fakültesi Restoratif Diş Tedavisi AD.
} 


\section{GİRİ̧}

Adeziv diş hekimliğinin başlangıcından itibaren kompozit rezinlerin dentin bağlanma dayanımını arttırmak amacıyla farklı kimyasal yapılara sahip adeziv sistemler üretilmiştir. İlk üretilen adezivlerin dentin bağlanma dayanımları zayıfken, nemli ortamda bağlanmayı sağlayan sistemlerin gelişmesiyle dentin adezivlerin bağlanma kuvvetleri arttırılmıştır. ${ }^{1}$ Adezivlerin etkinliğini arttırmak amacıyla yapılarına nem varlığında bağlanmayı sağlayan yüksek hidrofilik ve iyonik moleküller eklenmiştir. Yeni adeziv sistemler geliştirilirken üreticiler dentin bağlanma kuvvetini arttırmanın yanı sıra, uygulama aşamalarını azaltmayı da amaçlamışlardır.

Geleneksel çok aşamalı adeziv sistemler ayrı basamaklar halinde asit, primer ve bağlayıcı uygulamalarını içerir. Zaman kaybına neden olan bu prosedürü kolaylaştırmak amacıyla, primer ve bağlayıcı birleştirilerek 2 aşamada uygulanan adezivler geliştirilmiştir. Ardından mine ve dentinin ayrı birer basamakta asitlenmesini ortadan kaldıran 'Self-etch' adezivler geliştirilmiştir. Bu sistemde asit ve primer basamaklarının birleştirilmesi (self-etching primer) çalışma zamanını azaltıp, asidik jelin yıkanma safhasını ve aynı zamanda kollajenlerin aşırı kurumaya bağlı çökme riskini ortadan kaldırmıştır. Son olarak tüm işlemlerin tek bir basamakta toplandığı tek aşamalı (all in one) adezivler üretilmiştir. Tek aşamalı adezivler iki basamaklı self-etching primerlerden daha asidik ve hidrofiliktir. Hidrofilikliğin artması ile beraber bu sistemlerden suyu buharlaştırmak zorlaşmıştır, ayrıca su buharlaştırılsa da, adeziv uygulanmış dentinden adeziv rezin içerisine hızlıca geri difüze olmaktadır. ${ }^{2,3}$

İyi bir adezyon, yüksek bağlanma kuvveti, düşük mikrosızıntı ve uzun ömürlü restorasyonlar için oldukça önemlidir. Ancak kompozit rezin ile dentin arasındaki bağlanmanın uzun dönemli stabilitesi tam olarak aydınlatılamamıştır. ${ }^{4} 5$ Adeziv sistemlerin klinik başarısını etkileyen faktörlerden biri saklama koşullarıdır. Çoğu üretici firma tek aşamalı adezivlerin düşük sıcaklıkta bekletilmesini $\left(2-8^{\circ} \mathrm{C}\right)$ tavsiye etse de, pratikte bu adezivler üretici talimatlarından farklı koşullarda, örneğin oda sıcaklığındaki ortamlarda bekletilerek kullanılmaktadır. Adeziv materyalinin bekleme sıcaklığındaki değişiklikler bu materyalin polimerizasyonunu azaltarak fiziksel ve mekanik özelliklerini olumsuz etkileyebilir. ${ }^{6}$ Adezivin yüksek sıcaklıkta bekletilmesi polimerin viskozitesini arttırarak dentine penetrasyonunu ve bağlanma kuvvetini azaltabilirken, düşük sıcaklıkta bekletilmesi primerin buharlaşmasını azaltarak bağlanmayı arttırabilir. Primerin yapısındaki bu değişikliğin restorasyonun mikrosızıntısını da arttırdığı bildirilmiştir. $^{2}$

Yüksek sıcaklığın adeziv sistemlerin yapısını etkileyerek bağlanmayı azalttığı yönündeki bilgilere rağmen literatürde adeziv sistemlerin farklı sıcaklıklarda saklanmasının dentin bağlanma dayanımlarını etkilemediğini gösteren çalışmalar da mevcuttur ${ }^{7}, 8$. Spohr ve ark. ${ }^{7}$ adezivin bekleme sıcaklığının dentine bağlanma dayanımı üzerine etkisinin olmadığını bildirmiştir. Benzer şekilde Hagge ve ark. ${ }^{8}$ da oda sıcaklığında ve buzdolabında bekletmenin adezivin bağlanması üzerine olumsuz etkisinin olmadığını bildirmişlerdir. Sonuç olarak adezivlerin bekleme sıcaklığından ne derecede etkilendiği tartışmalı bir konudur.

Çalışmamızın amacı, tek aşamalı bir Self-Etch adezivin oda sıcaklığında ve buzdolabında 6 ay süreyle bekletilerek dentine uygulanması sonucunda elde edilen bağlanma dayanımlarını karşılaştırmaktır.

\section{GEREÇ VE YÖNTEM}

Çalışmada kullanılan adeziv ve kompozit rezinin içeriği Tablo 1' de belirtilmiştir. Bu çalışmada protetik, cerrahi ve periodontal sebeplerle çekilmiş 40 adet çürüksüz insan büyük azı dişi kullanıldı. Dişler, çekimden hemen sonra deney başlayıncaya kadar, altı ayı geçmeyecek şekilde, $4^{\circ} \mathrm{C}^{\prime}$ de distile su içerisinde bekletildi. Dentine kadar tüm dişlerin oklüzal yüzeyleri su soğutması altında düşük hızlı testere ile (Isomet 1000, Buehler Ltd., Lake Bluff, IL, Amerika) kesildi. Dentin yüzeyleri 600 gritlik silikon karbit zımpara ile su altında 60 sn süreyle zımparalanarak standart bir smear tabakası oluşturuldu ve adeziv rezinin bağlanmasına hazır hale getirildi. Çalışmada kullanılan adezivler üretim tarihini takiben üretici firmadan temin edildi. Bu adeziv sistemlerin birer seti 1 ay ve de 6 ay boyunca güneş Işı̆ıına maruz kalmadan, oda ISısında $\left(23 \pm 1^{\circ} \mathrm{C}\right)$ ve buzdolabında saklandı $\left(4 \pm 1^{\circ} \mathrm{C}\right)$. Üretim sonrası herhangi bir şekilde bekletilmemiş olan bir set dentin adeziv sistem ise, setlerin elimize ulaşmasını takiben $15 \pm 5$ gün içerisinde kontrol grubu olarak kullanıldı.

Dişler rastgele 5 gruba bölünerek gruplardan birine üretim sonrası bekletilmemiş bir şişe Clearfil $\mathrm{S}^{3}$ adeziv (Kuraray Dental, Okayama, Japonya) tek kullanımlık aplikatörle tüm dentin yüzeyine yayılacak şekilde uygulandı ve hafif hava ile kurutuldu.

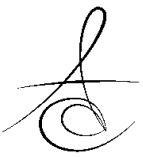


Atatürk Üniv. Diş Hek. Fak. Derg.

J Dent Fac Atatürk Uni

Cilt:28, Sayı:1, Yıl: 2018, Sayfa, 18-22
KARATAŞ, İŞCAN YAPAR, BAYINDIR
Tablo 1. Çalıșmada kullanılan materyaller ve içerikleri.

\begin{tabular}{|l|l|l|}
\hline Materyal & Türü & İceriği \\
\hline $\begin{array}{l}\text { Clearfil S }{ }^{3} \text { adeziv } \\
\text { (Kuraray Dental, } \\
\text { Okayama, Japonya) }\end{array}$ & $\begin{array}{l}\text { Tek aşamalı } \\
\text { Self-Etch } \\
\text { adeziv }\end{array}$ & $\begin{array}{l}\text { Hidrofobik-dimetakrilat, } \\
\text { etil alkol, kamforokinon, } \\
\text { Su, Silanize kolloidal silika }\end{array}$ \\
\hline $\begin{array}{l}\text { Grandio Kompozit } \\
\text { Rezin (Voco, } \\
\text { Cuxhaven, Almanya) }\end{array}$ & $\begin{array}{l}\text { Nanohibrit } \\
\text { kompozit } \\
\text { rezin }\end{array}$ & $\begin{array}{l}\text { BisGMA, BisEMA, } \\
\text { TEGDM, UDMA, Silanize } \\
\text { baryum aluminyum silikat } \\
\text { cam, hacimce\%80 } \\
\text { doldurucu }\end{array}$ \\
\hline
\end{tabular}

BisGMA: Bisfenol A diglisidil metakrilat, Bis-EMA: Etoksi bisfenol A glikol dimetakrilat, HEMA: Hidroksi Etil Metakrilat, TEG-DMA: Trietilen Glikol Dimetakrilat, UDMA: Üretan Dimetakrilat, MDP: Metakriloloksidesil dihidrojen fosfat.

Örneklere uygulanan adeziv rezinler $480 \mathrm{~nm}$ dalga boyu ve $1200 \mathrm{~mW} / \mathrm{mm}^{2}$ enerjiye sahip Elipar S10 LED ışık cihazı (3M Espe, Seefeld, Almanya) kulan larak $10 \mathrm{sn}$ ışıkla polimerize edildi. Polimerizasyon işleminden önce ışık cihazının gücü cihaza bağı radyometre ile kontrol edildi. Adeziv uygulamasının ardından tüm örneklerin üzerine politetrafluoroetilen kalıplar yardımıyla $3 \mathrm{~mm}$ çapında ve $4 \mathrm{~mm}$ yüksekliğinde kompozit silindirler (Grandio; Voco, Cuxhaven, Almanya) yerleştirildi. Kompozitlerin üzeri polystyrene bantla (KerrHawe Stopstrip, Bioggio, İsviçre) örtülerek düzleştirildi ve üretici talimatlarına uygun bir şekilde $20 \mathrm{sn}$ polimerize edildi (Elipar S10 LED, 3M Espe).

Tablo 2. Örneklerin başlangıç, 1 ay sonra ve 6 ay sonraki makaslama bağlanma dayanımı testi sonuçları

\begin{tabular}{|l|l|l|l|}
\hline $\begin{array}{l}\text { Bekleme } \\
\text { sıcaklığı }\end{array}$ & $\begin{array}{l}\text { Kontrol } \\
(\mathrm{MPa} \pm \mathrm{SD})\end{array}$ & $\begin{array}{l}1 \text { ay } \\
(\mathrm{MPa} \pm \mathrm{SD})\end{array}$ & $\begin{array}{l}6 \text { ay } \\
(\mathrm{MPa} \pm \mathrm{SD})\end{array}$ \\
\hline $\begin{array}{l}\text { Oda Sıcaklı̆ı̆ } \\
\left(23^{\circ} \mathrm{C}\right)\end{array}$ & $18,35 \pm 5,62^{\mathrm{a}}$ & $15,89 \pm 4,15^{\mathrm{a}}$ & $9,54 \pm 3,90^{\mathrm{b}}$ \\
\cline { 1 - 1 } $\begin{array}{l}\text { Buzdolabı } \\
\text { sıcaklığı }\left(4^{\circ} \mathrm{C}\right)\end{array}$ & & $17,71 \pm 2,87^{\mathrm{a}}$ & $16,85 \pm 6,03^{\mathrm{a}}$ \\
\hline
\end{tabular}

*Aynı harfler hem satır hem sütunlar arası istatistiksel olarak fark bulunmadığını göstermektedir ( $p>0.05)$.

Polimerizasyonu tamamlanan ve 24 saat süre ile $37^{\circ} \mathrm{C}$ distile suda bekletilen örneklere makaslama gerilme testi uygulamak için örnekler universal test cihazına (Instron Corp. Canton, MA, ABD) yerleştirilerek $1 \mathrm{~mm} / \mathrm{dk}$ hızla, kompozit silindir dentinden ayrılana kadar sabit bir noktadan kuvvet uygulandı. Newton cinsinden elde edilen değerler $\mathrm{MPa}=$ kuvvet $(\mathrm{N}) / a \operatorname{an}\left(\mathrm{mm}^{2}\right)$ formülü ile Megapaskala (MPa) çevrilerek kaydedildi. İlk örneklerin bağlanma dayanımları ölçüldükten sonra aynı üretim tarihine sahip biri buzdolabında $\left(+4 \pm 1^{\circ} \mathrm{C}\right)$ diğeri oda sıcaklığında ve güneş ışı̆ı̆na maruz kalmadan 1 ay ve 6 ay süre ile bekletilen iki şişe adeziv üreticilerin tavsiyeleri doğrultusunda örneklere uygulandı. Adeziv uygulanan örneklere ilk gruba benzer şekilde kompozit silindirler yerleştirilerek makaslama gerilme testi uygulandı. SPSS 20 yazilımıyla verilere Tek yönlü varyans analizi ve Post-hoc LSD çoklu karşılaştırma testi uygulandı. İki kategorili karşılaşıırmalar $\left(4^{\circ} \mathrm{C}\right.$ ve $23^{\circ} \mathrm{C}$ karşılaş̧ırmalarında) için ise Student's t Test uygulandı $(a=0.05)$.

\section{BULGULAR}

6 aylık süre sonunda makaslama gerilme testlerinin sonuçları Tablo $2^{\prime}$ de gösterilmiştir. Bu sonuçlara göre 1 ay süre sonunda oda sıcaklığında ve buzdolabında bekletilen adezivlerden hazırlanan örneklerle kontrol grubu arasında dentine bağlanma dayanımında istatistiksel olarak fark bulunmamıştır ( $p>0.05) .6$ ay sonunda ise oda sıcaklığında bekletilen adezivden hazırlanan örneklerin dentine bağlanma kuvvetleri, buzdolabında bekletilen adezivden hazırlanan örneklere göre istatistiksel olarak anlamlı derecede daha düşük bulunmuştur $(p<0.05)$. Her iki sıcaklıkta da bekleme süresi arttıkça bağlanma dayanımında azalma görülmüş, ancak bu azalma oda sıcaklğında 6 ay bekletilen örnekler dışında istatistiksel olarak önemli bulunmamıştır $(p>0.05)$.

\section{TARTIŞMA}

Çalışmamızda 1 ay ve 6 ay süre ile farklı sıcaklıklarda bekletilen bir Self-Etch adezivin dentin bağlanma dayanımı makaslama gerilme testi yöntemiyle karşılaştırımıştır. 1 ay süre sonunda adezivlerin dentin bağlanma dayanımları arasında farklı saklama sıcaklıkları açısından fark bulunmazken, 6 ay sonunda buzdolabında saklanan adezivin dentine bağlanma dayanımı oda sıcaklığında saklanan adezive göre istatistiksel olarak yüksek bulunmuştur.

Adeziv yapısına katılan primerin solvent türü dentin bağlanma dayanımı açısından önemli bir faktördür. Clearfil $S^{3}$ bond, su ve etanol esaslı primere sahiptir ve yapısında hidrofobik dimetakrilatlar içermektedir. ${ }^{9}$ Dimetakrilatlar suya dayanıklı değildir, zamanla şişe içerisinde hidrolize olarak metakrilik asit ve çapraz diollere dönüşürler. Araştırmalar bu ayrış-

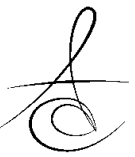


manın zamanla adezivin yapısını bozarak bağlanma dayanımını azalttığını tespit etmiştir. ${ }^{10}$ Çalışmamızda kullanılan adezivin ortalama bağlanma kuvvetinin zamana bağlı olarak azalması çapraz dimetakrilat bağlarının hidrolize olmasıyla açıklanabilir. Benzer şekilde Sadr ve ark. ${ }^{11} 60$ haftalık bekleme sürelerinde, 2 aşamalı ve tek şişe self etch adeziv sistemlerin (Clearfil SE Bond, Clearfil Tri-S Bond) farklı ısılarda dentine makaslama bağlanma dayanımlarını inceledikleri bir araştırmada; bekleme periodlarının sonunda $4^{\circ} \mathrm{C}$ ve $23^{\circ} \mathrm{C}^{\prime}$ de saklanan tek şişe self etch adeziv sistemde hiç beklememiş örneklere nazaran istatistiksel olarak anlamlı düşüş saptanırken, iki aşamalı self etch adeziv sistemlerde saptanan düşüş istatistiksel olarak anlamlı bulunmamıştır. Araştırmacılar tek şişe self etch adeziv sistemlerin suyla karıştııımış olması sebebiyle bu ajanların metakrilat monomerlerinde azalma olduğunu bildirmişlerdir. Araştırmacıların bu sonuçları çalışmamızın kontrol grubuna göre bağlanma sonuçlarını destekler niteliktedir.

Dentin adeziv sistemlerdeki kimyasal bozulmayı engellemek ve raf ömürlerini uzatabilmek adına bir çok yöntem düşünülmüş; bu malzemelerin buzdolabında veya oda ısısında saklanması önerilmiştir. ${ }^{12,13}$ Çalışmamızda oda sıcaklığında bekletilen örneklerin 6 ay sonunda dentin bağlanma dayanımında istatistiksel olarak önemli bir düşüş gözlenmiştir. Bu durum sıcaklık artışında adeziv içerisindeki dimetakrilatların daha fazla hidrolize olması ve adeziv yapısının daha fazla bozulması ile açıklanabilir. ${ }^{6}$ Çalışmamızla benzer şekilde Hagge ve ark..$^{14} 3$ farklı dentin adezivin $3^{\circ} \mathrm{C}$ ve $23.5^{\circ} \mathrm{C}$ saklama koşullarında dentine olan makaslama bağlanma dayanımlarını inceledikleri bir çalışmalarında; $3^{\circ} \mathrm{C}$ lik saklama koşullarında saklanan örneklerin, $23.5^{\circ} \mathrm{C}^{\prime}$ lik saklama koşullarında bekleyen örneklere göre daha yüksek bağlanma dayanımına sahip olduğunu göstermişlerdir. Nishiyama ve ark. ${ }^{15}$ 'da çalışmalarında adezivlerin oda sıcaklğında bekletilmesiyle daha yüksek bağlanma dayanımı elde etmişlerdir.

Literatürde adezivin saklandığı ortamın sıcaklığının dentin bağlanma dayanımını üzerinde önemli bir etkisinin olmadığını gösteren çalışmalar da mevcuttur. Spohr ve ark. ${ }^{16} 3$ farklı adeziv sistemin soğukta $\left(4^{\circ} \mathrm{C}\right)$ ve oda Isısında $\left(23^{\circ} \mathrm{C}\right)$ saklama sonrası gerilim bağlanma dayanımlarını araştırdıkları bir çalışmalarında; her iki ISı derecesinde de bağ dayanımlarında istatistiksel olarak anlamlı bir farkılılık olmadığını belirtilmişlerdir. Borges ve ark. ${ }^{17} 4^{\circ} \mathrm{C}$ ve $23^{\circ} \mathrm{C}^{\prime}$ de bekletilen dentin adeziv sistemlerin gerilim bağlanma kuvvetlerini ölçtükleri çalışmalarında her iki saklama koşullarında da istatistiksel olarak anlamlı farklılıklar saptamamışlardır. Ancak bu farklılık kullanılan adezivlerin yapısıyla, monomer içeriğiyle ve primer yapısındaki çözücünün farklı.ığıyla açıklanabilir. ${ }^{17}$

Çalışmamızın sonuçlarıyla bazı çalışmaların farklılık göstermesi her ajanın saklanma koşul ve periyodlarındaki dayanıkılıklarını ve ultra yapılarını inceleyecek daha fazla kimyasal ve analitik çalışmalara ihtiyaç olduğunu göstermektedir.

\section{SONUÇLAR}

Çalışmamızda tek aşamalı self etch bir adezivin saklama koşulları ve süreleri göz önüne alındığında, bağlanma değerlerinde saklama periyodları sonunda azalma olduğu görülmüştür. Bu nedenle dentin adezivlerin hızı tüketilmesi gerekmektedir. Bununla beraber en iyi performans sağlamak için adezivler üretici talimatlarına da uygun bir şekilde buzdolabında saklanabilir.

Özcan Karatas, ORCID ID: 0000-0002-6102-7675

Merve Işcan Yapar, ORCID ID: 0000-0002-9712-0978

Yusuf Ziya Bayındır, ORCID ID: 0000-0003-0943-1352

\section{KAYNAKLAR}

1. Garbui BU, Botta SB, Reis AF, Matos AB. Comparison of chemical aging and water immersion time on durability of resin-dentin interface produced by an etch-and-rinse adhesive. J Contemp Dent Pract 2012; 13: 464-71.

2. Mutluay MM, Yahyazadehfar M, Ryou $H$, Majd $H$, Do D, Arola D. Fatigue of the resin-dentin interface: a new approach for evaluating the durability of dentin bonds. Dent Mater 2013; 29 : 437-49.

3. Tay FR, Carvalho RM, Pashley DH. Water movement across bonded dentin - too much of a good thing. J Appl Oral Sci 2004; 12: 12-25.

4. Abdalla AI, El Zohairy AA, Aboushelib MM, Feilzer AJ. Influence of thermal and mechanical load cycling on the microtensile bond strength of selfetching adhesives. Am J Dent 2007; 20: 250-4.

5. Akın GE, Hergüner-Siso Ş, Akın H. Termal Siklus ve Suda Bekletmenin Kendinden Asitli Adezivlerin Dentine Mikrogerilim Bağlanma Dayanımları 
Üzerine Etkileri. Atatürk Üniv Diş Hek Fak Derg 2012; 22: 125-31.

6. Toledano M, Osorio R, Albaladejo A, Aguilera FS, Osorio $E$. Differential effect of in vitro degradation on resin-dentin bonds produced by self-etch versus total-etch adhesives. Journal of Biomedical Materials Research Part A 2006; 77: 128-35.

7. Spohr AM, Correr Sobrinho L, Consani $S$, Sinhoreti MA, Borges GA. Effect of refrigeration on tensile bond strength of three adhesive systems. Braz Dent J 2001; 12: 75-9.

8. Hagge MS, Lindemuth JS, Broome JC, Fox MJ. Effect of refrigeration on shear bond strength of three dentin bonding systems. Am J Dent 1999; 12: 131-3.

9. Poptani B, Gohil KS, Ganjiwale J, Shukla M. Microtensile dentin bond strength of fifth with five seventh-generation dentin bonding agents after thermocycling: An in vitro study. Contemp Clin Dent 2012; 3: 167-71.

10. Moszner N, Salz U, Zimmermann J. Chemical aspects of self-etching enamel-dentin adhesives: A systematic review. Dent Mater 2005; 21: 895-910.

11. Sadr A, Ghasemi A, Shimada Y, Tagami J. Effects of storage time and temprature on the properties of two sel-etching systems. J Dent 2007; 35: 21825.

12. Nishiyama N, Suzuki K, Yoshida H, Teshima H, Nemoto K. Hydrolytic stability of methacrylamide in acidic aqueous solution. Biomaterials 2004; 25: 965-9.

13. Davis EL, Joynt RB, Yu X, Wieczkowski G, Jr. Dentin bonding system shelf life and bond strength. Am J Dent 1993; 6: 229-31.

14. Hagge MS, Lindemuth JS, Broome JC, Fox MJ. Effect of refrigeration on shear bond strength of three dentin bonding systems. Am J Dent 1999; 12: 131-3.

15. Nishiyama N, Tay FR, Fujita K, Pashley DH, Ikemura $K$, Hiraishi N, King NM. Hydrolysis of functional monomers in a single-bottle self-etching primer - Correlation of C-13 NMR and TEM findings. J Dent Res 2006; 85: 422-6.

16. Spohr AM, Correr-Sobhirno L, Consani S, Sinhoreti MAC, Borges JA. Effect of refrigeration on tensile bond strength of three adhesive systems. Braz Dental J 2001; 12: 75-9.
17. Borges GA, Spohr AM, de Oliveira WJ, CorrerSobrinho L, Correr AB, Borges LH. Effect of refrigeration on bond strength of self-etching adhesive systems. Braz Dent J 2006; 17: 186-90.

\section{Yazışma Adresi}

Yrd. Doç. Dr. Merve İşCAN YAPAR

Atatürk Üniversitesi Diş Hekimliği Fakültesi Restoratif Diş Tedavisi A.D.

25240/ Erzurum, Türkiye.

Tel: 04422311811

E posta: dt.merveiscan@hotmail.com 